\title{
Topical 5\% potassium permanganate solution accelerates the healing process in chronic diabetic foot ulcers
}

\author{
IVÁN DELGADO-ENCISO ${ }^{1,2}$, VIOLETA M. MADRIGAL-PEREZ ${ }^{2}$, AGUSTIN LARA-ESQUEDA $^{1}$, \\ MARTHA G. DIAZ-SANCHEZ ${ }^{1}$, JOSE GUZMAN-ESQUIVEL ${ }^{1}$, LUIS E. ROSAS-VIZCAINO ${ }^{1}$, \\ OSCAR O. VIRGEN-JIMENEZ ${ }^{1}$, JULENY KLEIMAN-TRUJILLO ${ }^{1}$, MARIA R. LAGARDA-CANALES ${ }^{1}$, \\ GABRIEL CEJA-ESPIRITU ${ }^{2}$, VIRIDIANA RANGEL-SALGADO ${ }^{1}$, URIEL A. LOPEZ-LEMUS ${ }^{2}$, \\ JOSUEL DELGADO-ENCISO ${ }^{3}$, AGUSTIN D. LARA-BASULTO ${ }^{1}$ and ALEJANDRO D. SORIANO HERNÁNDEZ ${ }^{1,2}$ \\ ${ }^{1}$ Department of Research, Cancerology State Institute, Colima State Health Services, Colima 28085; \\ ${ }^{2}$ Department of Public Health, School of Medicine, University of Colima, Las Víboras, Colima 28040; \\ ${ }^{3}$ Department of Research, Foundation for Cancer Ethics, Education and Research \\ of the Cancerology State Institute, Colima 28085, Mexico
}

Received September 29, 2017; Accepted December 1, 2017

DOI: 10.3892/br.2018.1038

\begin{abstract}
Potassium permanganate has been reported to be an effective treatment for certain types of wounds. The aim of the present study was to evaluate the use of potassium permanganate in the treatment of diabetic foot ulcers. A single-blind, randomized, controlled clinical trial was conducted on patients with type 2 diabetes mellitus that presented with a foot ulcer persisting for $>3$ months. The control group $(n=10)$ was treated with the current standard treatment, which comprises of measures for reducing pressure in the ulcerated area, daily cleansing of the ulcer with potable water and antiseptic wash solution, and the application of a disinfectant solution on the entire surface area of the ulcer; while the intervention group $(n=15)$ received the standard treatment plus $5 \%$ topical potassium permanganate solution applied once a day for 21 days. In the intervention group, 1 patient did not tolerate the treatment and was eliminated from the study on the first day. The remaining patients tolerated the interventions well. At the end of the treatment period, ulcers in the control group had decreased by $38 \%$ whereas those in the intervention group decreased by $73 \%(\mathrm{P}<0.009)$. The degree of decrease was also investigated; the ulcer size was $\geq 50 \%$ decreased in $40 \%$ of patients in the control group and in $86 \%$ of patients in the intervention group $(\mathrm{P}=0.02)$. In conclusion, the results of the present study indicate that topical potassium permanganate is
\end{abstract}

Correspondence to: Dr Alejandro D. Soriano Hernández, Department of Research, Cancerology State Institute, Colima State Health Services, Avenue Liceo de Varones 401, Colonia La Esperanza, Colima 28085, Mexico

E-mail: gigiouxy@hotmail.com

Key words: diabetes, diabetic foot, treatment, potassium permanganate, Mexico well tolerated and significantly accelerates the healing process of diabetic foot ulcers.

\section{Introduction}

Type 2 diabetes mellitus (DM2) is a systemic, chronic-degenerative disease with a global prevalence of $9 \%$ in adults (1). It has been reported that $22-33 \%$ of adults $>65$ years of age in the United States have DM2 (1,2). Metabolic, vascular and neurologic complications are common in patients with DM2 and it is the most frequent cause of lower limb amputation (3). Approximately $25 \%$ of diabetic patients develop foot ulcers, which, if left untreated, may result in amputation (4).

Delayed wound healing in the diabetic foot is due to a number of factors, including elevated blood glucose levels, immune system deficiencies, peripheral arterial disease, peripheral neuropathy, foot deformity and secondary bacterial infection (4). In addition, the microenvironment of lesions in patients with diabetes is abnormal and pathogenic factors result in delayed closure of the ulcer and deficient formation of granulation tissue (5). Specifically, a persistent inflammatory infiltrate associated with bacterial colonization in the lesion may contribute to delay (5).

Despite recent advances in antimicrobial therapy $(6,7)$, diabetic foot lesions continue to be a serious problem. Foot ulcer treatments are lengthy, costly and require intensive care $(8,9)$. Alternative therapies, including topical treatments, have therefore been adopted to treat wounds (6-10). The use of several topical and systemic antibiotic agents has been halted due to the emergence of resistant strains (11). Given the increased prevalence of antibiotic-resistant pathogens, the use of mineral substances with antimicrobial activity, including potassium permanganate, may have potential as alternative treatments (12-15).

Potassium permanganate solution is a strong oxidizing agent that alters the cell walls of pathogenic organisms, interfering with their DNA structure and exerting potent microbicidal 
activity on bacteria, fungi, viruses and protozoa (13). It acts as an astringent and has a strongly alkaline $\mathrm{pH}$, producing immediate oxidation (13). In addition, it promotes the formation of granulation tissue and collagen synthesis, which are essential for the healing process $(13,15)$.

Potassium permanganate has previously been used to treat exuding wounds in dermatology and there is evidence that it acts on microbial species, fungi and the human immunodeficiency virus $(13,15)$. Despite its growing popularity in the treatment of exuding lesions and its contributions to their healing, to the best of our knowledge, there are limited studies on the effect of potassium permanganate on diabetic foot ulcers have been performed. The aim of the present study was to determine whether the topical application of $5 \%$ potassium permanganate solution could increase the efficacy of the current standard treatment for chronic diabetic foot ulcers.

\section{Patients and methods}

Patients. Adult patients with Wagner stage I (uninfected superficial ulcer) or II (deep ulcer, often infected, no bone involvement or abscesses) diabetic foot ulcers were enrolled in the present study $(5,11)$. The study was a simple-blind, randomized, controlled clinical trial conducted from March 2015 to November 2015. All patients had DM2 and presented with a chronic ulcer with a history of progression $>3$ months. Patients were recruited from an outpatient setting at the Medical Specialties Unit for Chronic Diseases at the Department of Health (Colima, Mexico) for diabetes control. A total of 25 patients (age range, 18-65 years; male-to-female ratio, 1:1.5) were enrolled in the present study. The clinical characteristics of the patients are presented in Table I. All patients signed statements of informed consent, and the present study was approved by the Ethics Committee of the Instituto Estatal de Cancerología (Colima, Mexico).

Groups and treatments. The 25 participating patients were randomly divided into 2 groups: The standard treatment group (control) and the experimental treatment group (intervention). The control group $(n=10)$ received the standard treatment for diabetic foot ulcers administered by the Colima State Health Services at the Department of Health (Colima). The standard treatment comprises measures for reducing pressure on the ulcerated area, daily cleansing of the ulcer with potable water and antiseptic wash solution, and the application of a super-oxidized disinfectant solution (Microdacyn ${ }^{\mathrm{TM}}$; TeArai BioFarma, Auckland, New Zealand) on the entire surface area of the ulcer. The patients were assessed every 7 days to evaluate the wound and debride the lesion if necessary. The intervention group $(n=15)$ received the same treatment as the control group except that $5 \%$ potassium permanganate solution (Vikút, Mexico City, Mexico) was used as a substitute for Microdacyn ${ }^{\mathrm{TM}}$. The potassium permanganate solution was applied once daily to the entire surface area of the ulcer with the wound as dry as possible. The wound was not washed or rinsed after the application of the potassium permanganate solution. In deep ulcers, excess solution was removed with dry, sterile gauze. The concentration of the potassium permanganate solution was chosen as $5 \%$ as this is the commercially
Table I. Clinical characteristics of the study subjects

\begin{tabular}{lccc}
\hline & \multicolumn{2}{c}{ Treatment } & \\
\cline { 2 - 3 } Clinical & $\begin{array}{c}\text { Standard } \\
\text { characteristics }\end{array}$ & $\begin{array}{c}\text { Experimental } \\
(\mathrm{n}=10)\end{array}$ & \\
\hline Men (\%) & 50.0 & 35.71 & 0.50 \\
Age (years) & $58 \pm 4.70$ & $53.50 \pm 2.34$ & 0.36 \\
Diabetes & $12.81 \pm 3.78$ & $12.14 \pm 3.43$ & 0.90 \\
duration (years) & & & \\
High blood & 50.0 & 21.40 & 0.10 \\
pressure $(\%)$ & & & \\
Hyperlipidemia $(\%)$ & 10.0 & 21.40 & 0.54 \\
Alcoholism $(\%)$ & 10.0 & 21.40 & 0.54 \\
Smoking $(\%)$ & 10.0 & 7.14 & 0.75 \\
Fasting glucose $(\mathrm{mg} / \mathrm{dl})$ & $140.11 \pm 19.81$ & $161.50 \pm 15.40$ & 0.40 \\
HbA1c $(\%)$ & $6.65 \pm 0.42$ & $7.83 \pm 1.35$ & 0.38 \\
Body mass index $\left(\mathrm{kg} / \mathrm{m}^{2}\right)$ & $30.61 \pm 1.74$ & $28.02 \pm 1.09$ & 0.20 \\
Ulcer area (mm $\left.{ }^{2}\right)$ & $5.38 \pm 1.24$ & $6.20 \pm 1.23$ & 0.65 \\
Days with ulcer & $114.00 \pm 61.95$ & $169.16 \pm 58.39$ & 0.56 \\
Wagner stage I $(\%)$ & 50.0 & 50.0 & 0.82 \\
Wagner stage II $(\%)$ & 50.0 & 50.0 & 0.82 \\
Local infection $(\%)$ & 20.0 & 64.28 & 0.03 \\
& & &
\end{tabular}

HbA1c, glycated hemoglobin. ${ }^{a}$ Of the 15 patients initially included, 1 was withdrawn from the trial due to potassium permanganate intolerance; this patient's clinical data was not included in analysis.

available pharmacologic concentration for use as a topical antiseptic. Metabolic control measures for diabetes were continued as usual in all the patients.

Ulcer assessment. The ulcer area was measured upon admission (day 0) and on days 7, 14 and 21 by placing a piece of transparent acetate over the ulcer and outlining it with a permanent ink marker. The contour of the ulcer was digitalized as previously described $(16,17)$ and the area calculations were made using ImageJ v1.51 software following the manufacturer's instructions (National Institutes of Health, Bethesda, MD, USA). The ulcer area at day 0 was recorded as $100 \%$. The physician who assessed ulcer areas was blinded to the patient group.

Statistical analysis. Normal distribution of data was confirmed using the Shapiro-Wilk test. The Student's t-test was used to make comparisons between groups. Categorical values were compared using Fisher's exact test. Relative risk (RR) was calculated to determine the probability of a $\geq 50 \%$ reduction of the ulcer area at day 21 in the intervention group compared with the control. The number-needed-to-treat (NNT) was defined as the number of individuals receiving the experimental treatment necessary to give an additional beneficial effect (a 50\% ulcer reduction on day 21) compared with the control group. The $95 \%$ confidence interval (CI) was calculated for the RR and NNT. Statistical analysis was performed using SPSS software, version 20 (IBM Corp., Armonk, NY, USA) with the exception of the NNT, which was calculated using MedCalc v17.7.2 software (MedCalc Software bvba, Ostend, Belgium). 


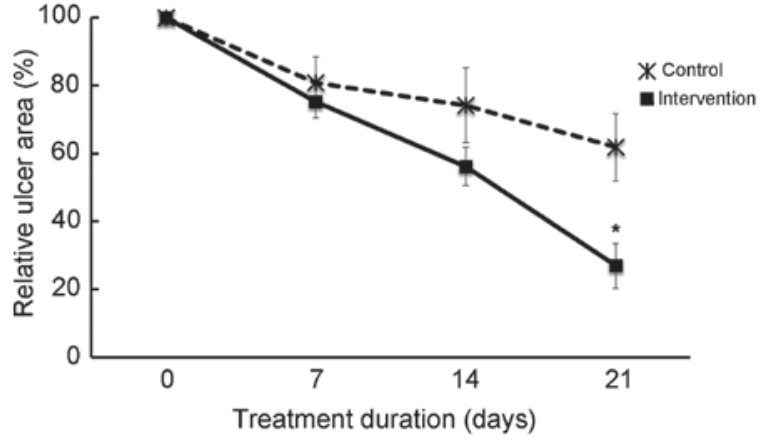

Figure 1. Ulcer area progression in the control and intervention groups. The mean ulcer area of patients treated with $5 \%$ potassium permanganate solution was significantly lower compared with those receiving the standard treatment for 21 days. ${ }^{*} \mathrm{P}<0.009$ vs. standard treatment.

$\mathrm{P}<0.05$ was considered to indicate a statistically significant difference.

\section{Results}

Baseline characteristics. Patient characteristics, pathological history, ulcer presentation and size were similar between the two groups (Table I). Only the infected ulcer percentage was significantly higher in the intervention group $(\mathrm{P}=0.03$; Table I).

Treatment tolerance. On the first day of the trial, 1 patient complained of pain and intolerance upon application of the potassium permanganate solution. Its application was suspended, and there were no subsequent adverse effects. The patient was withdrawn from the study and continued to receive standard treatment outside of the clinical trial, leaving a total of 14 patients in the intervention group. All patients in the intervention group stated that the potassium permanganate solution produced a warm sensation, however this was well tolerated.

Clinical efficacy of potassium permanganate solution. Ulcer reduction was observed in the intervention group from day 7 , and at day 21 the ulcer area was significantly decreased compared with the control group $(\mathrm{P}<0.009)$; at day 21 the mean reduction in ulcer size was $73 \%$ in the intervention group and $38 \%$ in the standard treatment group (Fig. 1). Furthermore, at day 21 , the ulcer size in $86 \%$ of intervention group patients was reduced by at $\geq 50 \%$; however, in the control group only $40 \%$ of patients achieved $\geq 50 \%$ reduction (RR, 3; 95\% CI, 1.1-7.6; $\mathrm{P}=0.02$; data not shown). The NNT with potassium permanganate to produce the benefit of $\geq 50 \%$ reduced ulcer size at day 21 was 2.18 (95\% CI, 1.26-8.25; data not shown).

Complete healing of the ulcer occurred in 4 of the 14 patients $(29 \%)$ in the intervention group following 3 weeks of treatment, whereas complete healing was not observed in any control patients during the study period (data not shown). Progression after day 21 was not analyzed.

\section{Discussion}

Topical application of 5\% potassium permanganate solution, in addition to the standard treatment and cleansing regimen, accelerated the healing process of chronic diabetic foot ulcers compared with standard treatment alone. A $\geq 50 \%$ reduction in ulcer size was observed in $86 \%$ of patients following 21 days of potassium permanganate treatment, compared with $40 \%$ of patients receiving standard treatment. The complementary use of potassium permanganate for wound treatment has not been widely studied and is generally limited to clinical case studies. To the best of our knowledge, the present study is the first demonstrating the efficacy of potassium permanganate as a treatment for diabetic foot ulcers. Previous studies have demonstrated that potassium permanganate solution is an effective auxiliary treatment for weeping varicose eczema $(18,19)$. One study investigated patients with gas gangrene as a complication of trauma wounds, and the results indicated that potassium permanganate treatment helped to eliminate the anaerobic microenvironment and had a therapeutic effect on wound healing (20). In another study, $1 \%$ potassium permanganate solution was applied 3 or 4 times a day to infected and fetid ulcerations in advanced tumors (21). No quantitative data on patient improvement was included, however the authors reported a clinical improvement of the infection and fetidness without the use of local or systemic antibiotics (21).

The benefits of potassium permanganate include lower cost, a reduced rate of allergies and a significantly higher healing rate compared with other medications (18-20). However, the $5 \%$ concentration of potassium permanganate used in the present study was higher than other reported concentrations (0.01 and 1\%) (20-22), which should be considered in future studies or comparisons. The patients in the intervention group had a 3-fold greater probability of a $\geq 50 \%$ ulcer reduction following 3 weeks of treatment compared with patients receiving standard treatment. The standard treatment used in the control group included a disinfectant (a super-oxidized solution with a neutral $\mathrm{pH}$ ) that has previously been reported to effectively improve granulation and ameliorate ulcer infections in the diabetic food (22), making it a good reference for evaluating the effectiveness of $5 \%$ potassium permanganate solution.

Amputations are used to delimit systemic damage caused by gangrene or infection. Complicated diabetic foot ulcers often result in major or minor amputations that greatly impact patient life expectancy and quality of life (20), as well as having serious economic repercussions $(9,22)$. Potassium permanganate is a strong oxidizing agent that may help to eliminate the anaerobic microenvironment necessary for the growth of bacteria, including those of the genus Clostridia and other pathogenic bacteria (20). It has previously been demonstrated that lavages with potassium permanganate solution have a therapeutic effect, even in mixed infections (20). The application of potassium permanganate may therefore be beneficial for fighting infections, possibly reducing their progression in addition to accelerating the healing process of diabetic foot ulcers. The present study included patients with superficial and deep ulcers with no abscesses, classified as Wagner stages I and II. One limitation was that ulcer depth was not assessed. Future studies should include this measurement and also investigate the effect of potassium permanganate solution on severely infected ulcers with concomitant abscesses or gangrene (Wagner stages III or IV). 
In the intervention group, $1 / 15$ patients did not tolerate the potassium permanganate treatment, however they experienced no adverse effects once the application was stopped. A high tolerance for topical potassium permanganate treatment has been described in previous studies (18-21). There is no evidence that topical application of potassium permanganate raises plasma potassium levels (20). However, when used at higher concentrations than described in the present study, topical application may cause chemical burns and there have been studies of harmful effects associated with the accidental ingestion of potassium permanganate solution $(23,24)$. Studies on homemade potassium permanganate solutions, prepared by dissolving commercially available tablets or crystals intended for nonmedical use, have indicated that solid fragments of potassium permanganate may come into contact with the skin and cause caustic burns if the tablets or crystals are not completely dissolved (24).

The present study had several limitations, including the small sample size and the fact that ulcer progression was not analyzed beyond day 21 . Future studies should include a larger number of patients with a longer follow-up period to further investigate the treatment response of diabetic foot ulcers.

In conclusion, the present study demonstrated that $5 \%$ potassium permanganate solution as a complementary treatment for diabetic foot ulcers is well tolerated and viable, effectively accelerating the healing process of diabetic foot ulcers of Wagner stages I and II. These data support the use of $5 \%$ potassium permanganate as a topical alternative to conventional antibiotics and antiseptic agents.

\section{Acknowledgements}

The present study was supported by grants INFRAESTRUCTURA-CONACYT-2016 (grant no. 270485) and FOSISSCONACYT-2016 (grant no. 272792).

\section{References}

1. Yakaryılmaz FD and Öztürk ZA: Treatment of type 2 diabetes mellitus in the elderly. World J Diabetes 8: 278-285, 2017.

2. Villalpando S, de la Cruz V, Rojas R, Shamah-Levy T, Avila MA, Gaona B, Rebollar R and Hernández L: Prevalence and distribution of type 2 diabetes mellitus in Mexican adult population: A probabilistic survey. Salud Publica Mex 52 (Suppl 1): S19-S26, 2010.

3. Hernández-Ávila M, Gutiérrez JP and Reynoso-Noverón N: Diabetes mellitus in Mexico. Status of the epidemic. Salud Publica Mex 55 (Suppl 2): S129-S136, 2013 (In Spanish).

4. Escobedo-de la Peña J and Rico-Verdín B: Incidence and fatality of the acute and chronic complications of diabetes mellitus in Mexico. Salud Publica Mex 38: 236-242, 1996 (In Spanish).

5. Cavanagh PR, Lipsky BA, Bradbury AW and Botek G: Treatment for diabetic foot ulcers. Lancet 366: 1725-1735, 2005.

6. Adeghate J, Nurulain S, Tekes K, Fehér E, Kalász H and Adeghate E: Novel biological therapies for the treatment of diabetic foot ulcers. Expert Opin Biol Ther 17: 979-987, 2017.
7. Dalla Paola L, Carone A, Boscarino G, Scavone G and Vasilache L: Combination of open subtotal calcanectomy and stabilization with external fixation as limb salvage procedure in hindfoot-infected diabetic foot ulcers. Int J Low Extrem Wounds 15: 332-337, 2016.

8. Joret MO, Dean A, Cao C, Stewart J and Bhamidipaty V: The financial burden of surgical and endovascular treatment of diabetic foot wounds. J Vasc Surg 64: 648-655, 2016.

9. Danmusa UM, Terhile I, Nasir IA, Ahmad AA and Muhammad HY: Prevalence and healthcare costs associated with the management of diabetic foot ulcer in patients attending Ahmadu Bello University Teaching Hospital, Nigeria. Int J Health Sci (Qassim) 10: 219-228, 2016.

10. Bowling FL, Rashid ST and Boulton AJ: Preventing and treating foot complications associated with diabetes mellitus. Nat Rev Endocrinol 11: 606-616, 2015.

11. Falanga V: Wound healing and its impairment in the diabetic foot. Lancet 366: 1736-1743, 2005.

12. Payne DJ, Gwynn MN, Holmes DJ and Pompliano DL: Drugs for bad bugs: Confronting the challenges of antibacterial discovery. Nat Rev Drug Discov 6: 29-40, 2007.

13. Sánchez-Saldaña L and Sáenz Anduaga E: Antisépticos y desinfectantes. Dermatol Peru 15: 82-103, 2005. http://metabase.uaem. $\mathrm{mx} /$ bitstream/handle/123456789/1468/280_4.pdf.

14. Majtan J: Methylglyoxal - a potential risk factor of manuka honey in healing of diabetic ulcers. Evid Based Complement Alternat Med 2011: 295494, 2011. doi: 10.1093/ecam/neq013.

15. Anderson I: Should potassium permanganate be used in wound care? Nurs Times 99: 61, 2003.

16. Liu R, Li L, Yang M, Boden G and Yang G: Systematic review of the effectiveness of hyperbaric oxygenation therapy in the management of chronic diabetic foot ulcers. Mayo Clin Proc 88: 166-175, 2013.

17. Xu L, McLennan SV, Lo L, Natfaji A, Bolton T, Liu Y, Twigg SM and Yue DK: Bacterial load predicts healing rate in neuropathic diabetic foot ulcers. Diabetes Care 30: 378-380, 2007.

18. Quartey-Papafio CM: Lesson of the week: Importance of distinguishing between cellulitis and varicose eczema of the leg. BMJ 318: 1672-1673, 1999.

19. Biswas M, Gibby O, Ivanova-Stoilova T and Harding K: Cushing's syndrome and chronic venous ulceration - a clinical challenge. Int Wound J 8: 99-102, 2011.

20. Hu N, Wu XH, Liu R, Yang SH, Huang W, Jiang DM, Wu Q, Xia T, Shao ZW and Ye ZW: Novel application of vacuum sealing drainage with continuous irrigation of potassium permanganate for managing infective wounds of gas gangrene. J Huazhong Univ Sci Technolog Med Sci 35: 563-568, 2015.

21. Dulciné-Roque R, Pullés-González V and Gutierrez-González L: Eficiencia del Permanganato de Potasio aplicado en las heridas septicas en el servicio de cirugia cervico-facial. Santiago de Cuba, Centro Provincial de Información de Ciencias Médicas de Santiago de Cuba, volume 1, pp. 1-10 1995.

22. Martínez-De Jesús FR, Ramos-De la Medina A, Remes-Troche JM, Armstrong DG, Wu SC, Lázaro Martínez JL and Beneit-Montesinos JV: Efficacy and safety of neutral $\mathrm{pH}$ superoxidised solution in severe diabetic foot infections. Int Wound J 4: 353-362, 2007.

23. Johnson TB and Cassidy DD: Unintentional ingestion of potassium permanganate. Pediatr Emerg Care 20: 185-187, 2004.

24. Baron S and Moss C: Caustic burn caused by potassium permanganate. Arch Dis Child 88: 96, 2003.

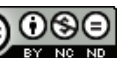

This work is licensed under a Creative Commons Attribution-NonCommercial-NoDerivatives 4.0 International (CC BY-NC-ND 4.0) License. 